\title{
LA CUEVA DE LA MURCIELAGUINA, EN PRIEGO DE CÓRDOBA, POSIBLE CUEVA - SANTUARIO IBÉRICA
}

\author{
DESIDERIO VAQUERIZO GIL \\ Universidad de Córdoba
}

\begin{abstract}
El presente trabajo plantea un análisis de los materiales de época ibérica recogidos en superficic en la llamada Cueva de la Murcielaguina, localizada en el término municipal de Priego de Córdoba. Dichos materiales, entre los cuales se encuentra una cabecita tallada en piedra caliza, llevan al autor a plantear la existencia en Andalucía de cuevas santuarios similares a las constatadas en el mundo levantino.

En este caso, la cueva, en la que debieron celebrarse ciertos ritos relacionados con ceremonias de libación y tal vez conectados con una Gran Diosa Madre - con cuyo culto se identifica un ídolo oculado representando entre las pinturas rupestres que adoman una de las salas interiores- estaría en relación con poblados cercanos tan importantes como El Camino del Tarajal (Priego de Córdoba), Cerro de Las Cabezas (Fuente Tójar) o Cerro de la Cruz (Almedinilla), este último actualmente en excavación por parte del autor.
\end{abstract}

The article deals with the analysis of Iberian-age materials found on surface in the cave of "La Murcielaguina», at Priego (Córdoba). Among these objets there is a small calcareous head which leads the author to think in the existence of sanctuary-caves in Andalucia similar to the Levantine culture ones.

The cave, in which some rites could have been posibly celebrated in relation to the libation ceremony and the Great Mother Goodess cult (testified in the past by an oculate idol painted an inner room wall of the cave) must be put together with the archaeological discoveries of other important deposits, such as «Camino del Tarajal» (Priego de Córdoba), «Cerro de las Cabezas» (Fuente Tójar) and «Cerro de la Cruz» (Almedinilla). This last one is at present under study by the author.

Desde los geógrafos árabes a la Corografía de Casas Deza (RAMÍREZ Y DE LAS CASAS DEZA, 1840) el reino o provincia de Córdoba se venía dividiendo en Sierra Morena y Campiña. Sin embargo, desde el punto de vista fundamentalmente geológico y de relieve, en la actual provincia cordobesa se pueden distinguir tres grandes áreas que corresponden a la Sierra Morena, la Campiña y las Sierras Subbéticas, formadas, respectivamente, por terrenos paleozoicos, terciarios-cuaternarios y mesozoicos.

En concreto, el marco subbético cordobés (Fig. 1) se caracteriza por su mayor elevación en relación con los terrenos colindantes y, en esencia, presenta como rasgo básico su heterogeneidad en lo físico, con relieve accidentado, litología y suelos de distribución laberíntica y clima irregular. Es una zona de colinas y barranqueras de perfiles muy heterogéneos, con una serie de macizos montañosos cuyas alturas oscilan por lo general entre los $1.000 \mathrm{y}$ los 1.500 ms. y que, básicamente, configuran un relieve descarnado, con enormes extensiones de afloramientos calizos y calizo-dolomíticos, incapaces de sustentar suelos aptos para la vegetación y la agricultura y con una gran abundancia de acuíferos, debido tanto a la alta pluviosidd como al fuerte coeficiente de infiltración, favorecido sobre todo por las formas de carácter kárstico (ORTEGA ALBA, 1974, 27 ss; LÓPEZ ONTIVEROS, 1985) (1). 


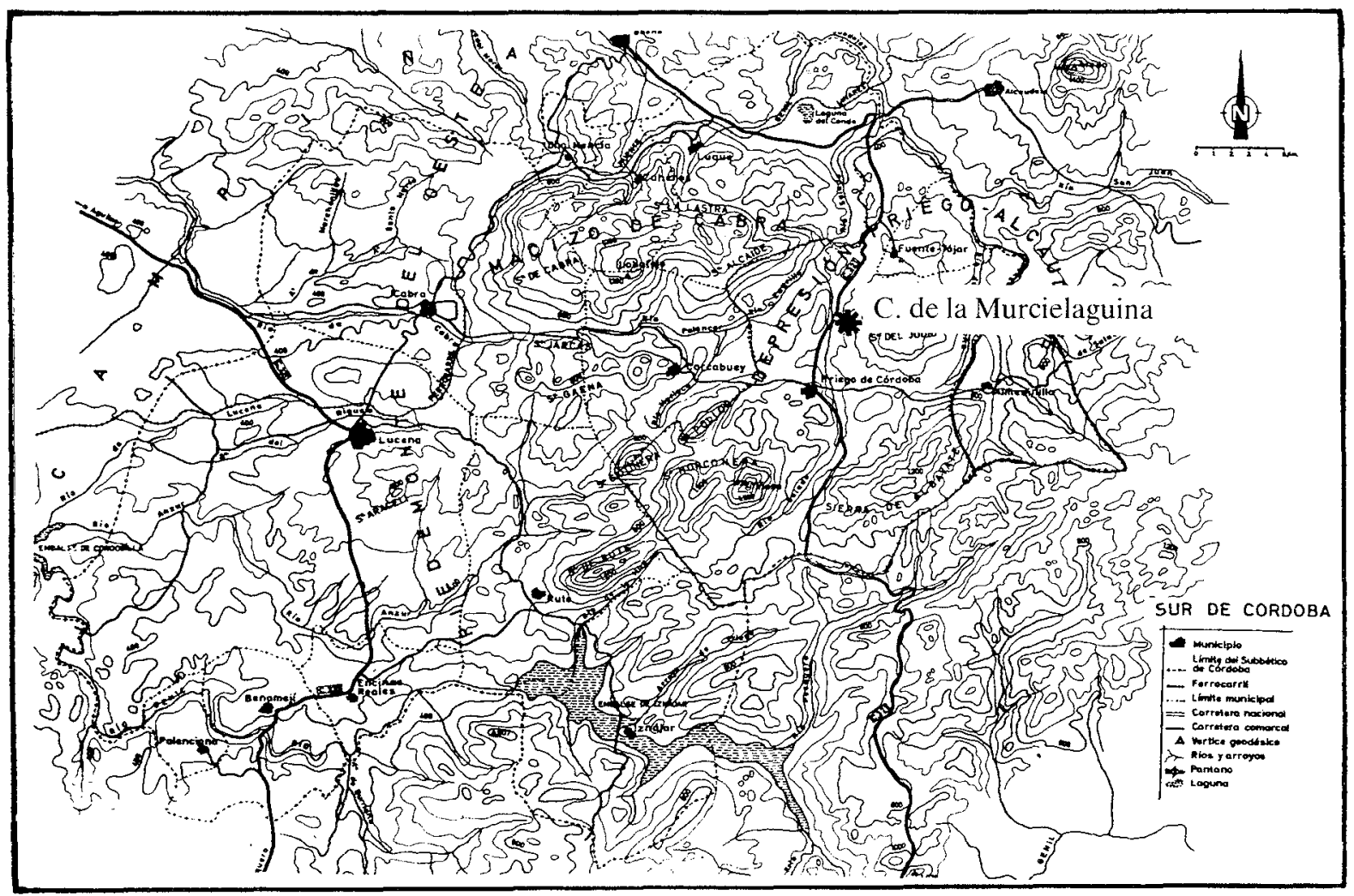

Fig. 1.-La Subbética Cordobesa. División estructural. Localización de la Cueva de la Murcielaguina, dominando el desfiladero de las Angosturas, por el que discurre actualmente la carretera comarcal 321. (Según ORTEGA ALBA, 1975. gráf. 3).

Pues bien, la llamada Cueva de la Murcielaguina (M.T.N. E: 1/50000 Hoja 990: Alcalá la Real; Coordenadas: $\left.37 .^{\circ} 28^{\prime} 41^{\prime \prime} \mathrm{N} ; 0 .^{\circ} 29^{\prime} 35^{\prime \prime} \mathrm{W}\right)$, ubicada en pleno relieve subbético, se abre en la ladera W del paso de Las Angosturas, desfiladero crucial en el camino de Córdoba a Granada por Almedinilla y Alcalá la Real, en cuyas inmediaciones se localiza también la Cueva de Huerta Anguita, y pertenece al término municipal de Priego de Córdoba. Es una zona en la que, debido a su relieve calizo, abundan las formas kársticas y como ejemplos se pueden destacar la importante estación de los Már-

(1) ORTEGA ALBA, F., 1974: Esta obra constituye aún hoy, a más de 10 años de su publicación, la base fundamental para el estudio de esta comarca, tanto desde el punto de vista estrictamente físico como en el geográfico más amplio. Con posterioridad ha sido reactualizada y completada por A. LÓPEZ ONTIVEROS (1985) quien ha elaborado, aunque a título indiscutiblemente divulgativo, la tesis más completa hasta el momento sobre la geografía cordobesa. moles, al SE, actualmente en excavación por parte de M. ${ }^{a}$ Dolores Asquerino y Beatriz Gavilán, y, no muy lejos, al NW, ya en término municipal de $\mathrm{Zu}$ heros, la conocida Cueva de los Murciélagos, primer hito de importancia en el panorama arqueológico del Neolítico cordobés.

Ahora bien, no todas las cuevas constatadas conservan restos de haber sido ocupadas - por múltiples causas que van desde su difícil habitabilidad hasta su deterioro por causas antrópicas-y en las que esa ocupación ha sido probada (GAVILÁN CEBALLOS, 1983 y 1984) (2) no siempre se ha señalado la presencia de materiales posteriores

(2) En la actualidad, el Neolítico cordobés es objeto de estudio por parte de las Prof. M. ${ }^{a}$ Dolores Asquerino y Beatriz. Gavilán, quienes, a través de diversas excavaciones e intensas prospecciones del territorio provincial se hallan elaborando una sistematización de dicho periodo que puede arrojar mucha luz. para su interpretación en el Sur peninsular. 


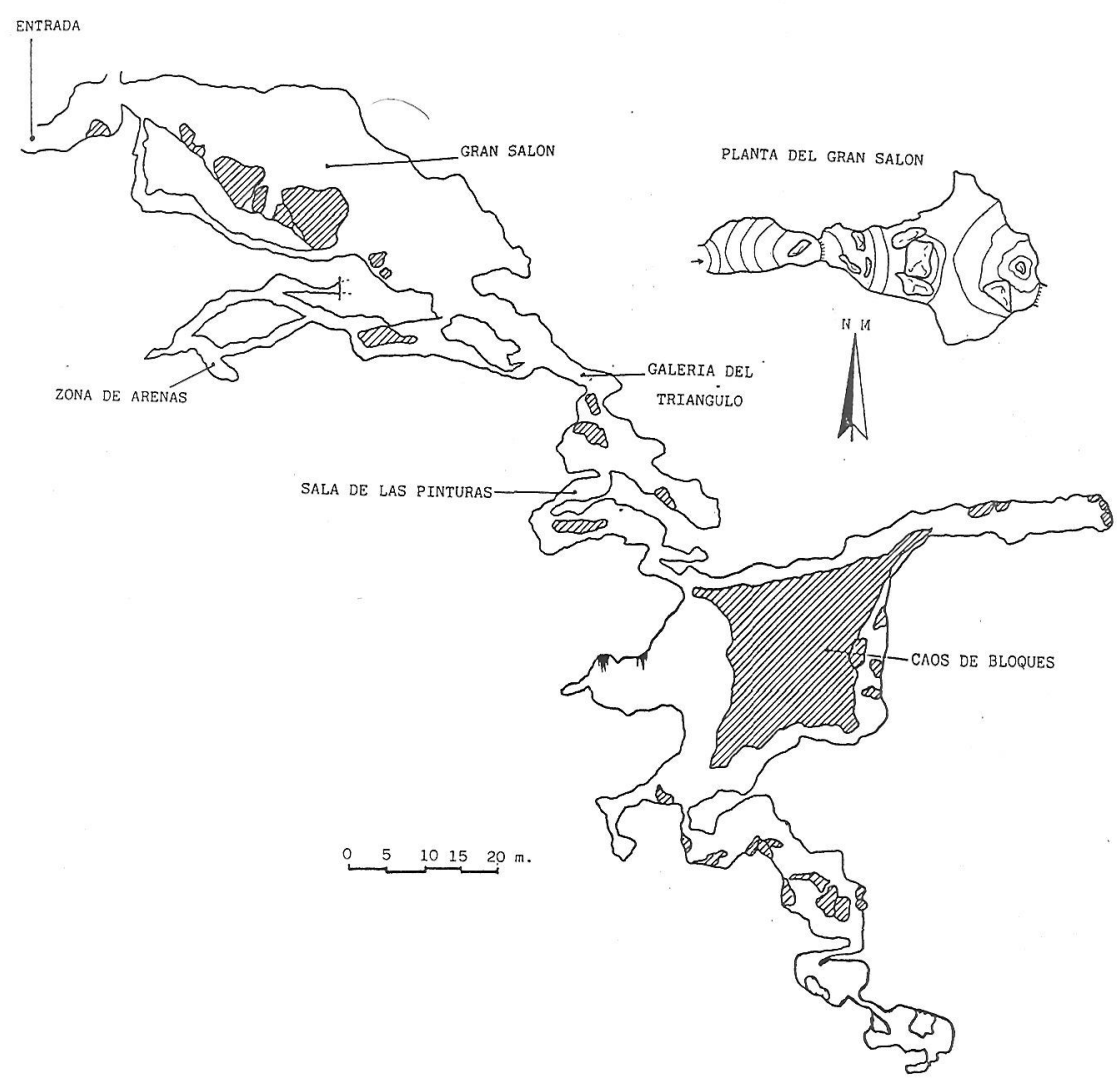

Fig. 2.-Desarrollo Topográfico de la Cueva de la Murcielaguina, en la que se observa la dificultad de su trazado, sujeto a continuas variaciones. (Según GAVILÁN CEBALLOS, 1981).

al Bronce, tal vez por haber sido la época neolítica el objetivo fundamental de su estudio y catalogación. Aún así, en varias de ellas: Murciélagos, Cholones, Mármoles, Huerta Anguita... se ha comprobado su utilización en época romana, tardorromana y musulmana. Empero, no ocurre lo mismo con el período que denominamos ibérico y en esta característica reside precisamente uno de los aspectos más destacados de la Cueva de la Murcielaguina, cuyo aspecto cronológico - aunque impreciso- abarca al menos desde el Neolítico Medio hasta época medieval, con algunos hipotéticos hiatos correspondientes al Bronce Pleno y Final y a época romana imperial que muy posiblemente responden al azar de los hallazgos y a las características especiales de la cueva.

La entrada de la cavidad, de forma ligeramente trapezoidal (LAM. I), presenta unos $4 \mathrm{~ms}$. de altura por 3 de anchura y se halla orientada al NW. Esta entrada da paso a un vestíbulo de unos $10 \mathrm{~m}$. de longitud por 6 de anchura cubierto por bloques de aporte endógeno (Fig. 2) y, a continuación, se ac- cede a una amplia oquedad, denominada «Gran Salón», cuyo suelo aparece hoy cubierto por grandes bloques desprendidos del techo que se halla totalmente revestidos de murcielaguina - de donde el nombre asignado a la cueva-. A partir de aquí, el trazado de la cueva se vuelve laberíntico, observándose en muy escasas oportunidades el suelo real de la misma y, en general, desciende de manera helicoidal hasta prácticamente la capa freática, siendo muy complicado y peligroso su recorrido (GAVILÁN CEBALLOS, 1983). Hoy, la Cueva de la Murcielaguina, de inmejorables condiciones para el hábitat, se encuentra en un proceso de progresiva degeneración morfológica - hecho al que han contribuído las voladuras efectuadas para la apertura de la N-321; la contínua afluencia de visitantes, por su proximidad a Priego y su relativamente fácil acceso, y la acción de los excavadores clandestinos, que han llegado incluso a desfigurar salas completas- $y$, en definitiva, la descripción de su forma real resulta complicada en extremo por la enorme cantidad de bloques caídos, a causa de la 


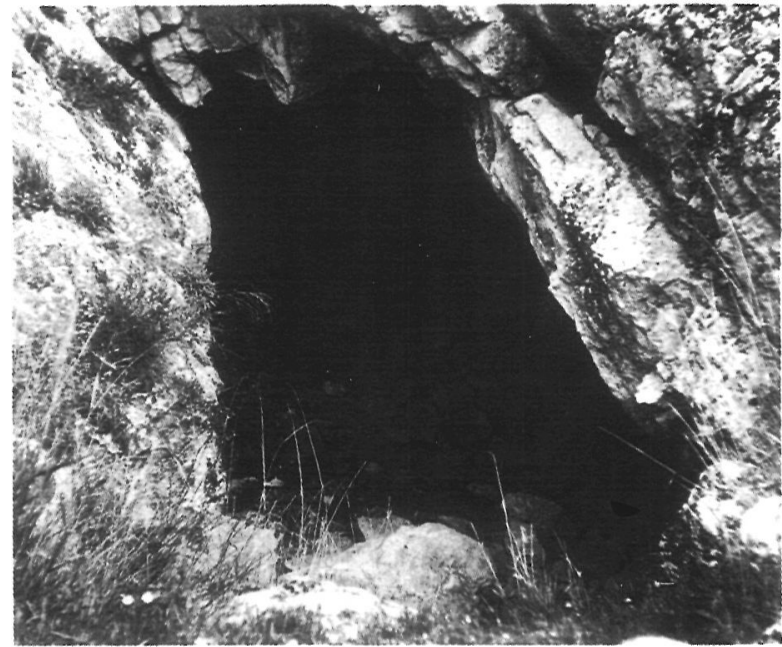

Lám. I:Entrada a la Cueva de la Murcielaguina, abierta sobre el Paso de las Angosturas. Al fondo, el vestíbulo donde apareció parte del material que presentamos.

descalcificación, que en ocasiones impiden el paso y que, con frecuencia, desdibujan el trazado verdadero de las salas provocando impresiones engañosas en cuanto a su disposición y dimensiones.

En la mayor parte de las salas aparece un profuso material cerámico, casi en su totalidad neolítico - con cerámicas incisas, impresas a la almagra de gran calidad y bastas que se remontan al menos hasta el Neolítico Medio- y en la llamada «Sala de las Pinturas», hoy prácticamente inaccesible, se localizan abundantes representaciones de carácter estrictamente esquemático entre las cuales destaca un ídolo oculado cuya iconografía, de tipo oriental, se relaciona con la Gran Diosa Madre, o Diosa de la Tierra. Son fechadas en el transcurso del Bronce I Hispánico (BERNIER Y FORTEA, 196869, 143-165).

En cuanto al material que presentamos, adscribible todo él a época ibérica, fue recogido en una de las salas interiores de la cueva y, sobre todo, en la amplia cavidad que hace las veces de vestíbulo. Ahora bien, no hay que olvidar que el interior resulta hoy prácticamente inaccesible, por lo que es muy arriesgado el afirmar que dicho material fue depositado tan sólo en ambas salas y, por otra parte, tanto en uno como en otro aparece revuelto a gran cantidad de clastos y algunas cerámicas de otras épocas, todo lo cual hace imposible puntualizar más en cuanto a su localización, limitándose, pues, a presentar una breve muestra del mismo, en-
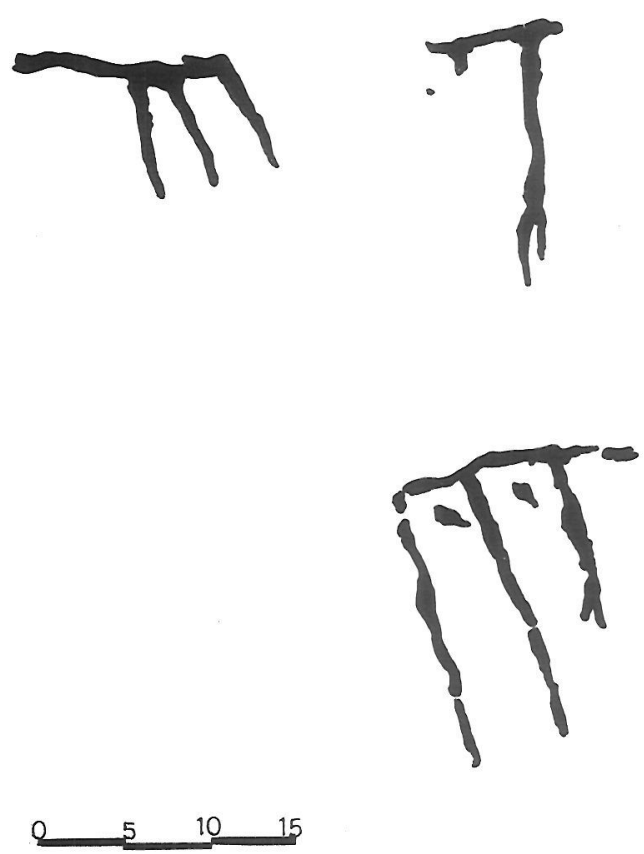

Fig. 3.-Cueva de la Murcielaguina. Pinturas rupestres. Panel IV, en el que se observa, en el ángulo inferior derecho, un ídolo oculado. (Según BERNIER y FORTEA, 1968-69).

tre el que se cuenta una cabecita fragmentada que describiremos a continuación.

Respecto a la cerámica, se trata en todos los casos de platos, cuencos y algunas formas caliciformes en las que predominan las pastas claras, oscilando entre el marrón, el ocre y el rojo ladrillo. Sólo en uno de los casos (Fig. 5, 7) un caliciforme presenta la pasta gris y sólo uno también de los pequeños vasos (Fig. 4, 2) ofrece decoración pintada, consistente en una banda rojo vinoso en la parte superior del borde y otra de color negro en el interior. Se trata siempre de formas de pequeño tamaño y posiblemente fueron destinadas a algún tipo de ofrenda o libación, siendo quizás rotas a continuación como parte del mismo rito.

Por su parte la escultura, que fue hallada entre los numerosos clastos desprendidos de techos y paredes al realizar una prospección de la cueva en 1984 (3), consiste en un pequeño bloque de caliza de color marrón amarilleto, fragmentado de forma irregular y que sólo conserva huellas de talla en la parte correspondiente al rostro (LAM. II). Este ha 
sido esculpido de forma muy sumaria, procediendo a su alisado posterior, y en él los rasgos responden a un marcado esquematismo que indica las cejas mediante una simple incisión; los ojos mediante un circulito inciso situado prácticamente en el mismo plano que las cejas; la nariz, que arranca desde estas últimas, con una cierta forma parabólica acentuada por una línea incisa en el lado derecho $y$, por fin, la boca como un simple trazo horizontal remarcado mediante un fuerte plano biselado que hace las veces de labio inferior y que, en realidad, se une a la barbilla. No conserva ninguna huella del tratamiento de las orejas ni del pelo y tan sólo en el lado izquierdo se observa un cambio de plano que indica el arranque del cuello, lo cual nos da prueba de que, en su origen, la pieza debió ser esculpida al menos como un busto completo, muy posiblemente de bulto redondo - a juzgar por el grosor del bloque utilizado-. Sus dimensiones actuales son $13 \mathrm{cms}$. de altura plor 9'8 de grosor máximo.

En cuanto a la cronología, la escasez de materiales dificulta el establecimiento de una secuencia cronológica concreta. Los vasos caliciformes grises perduran a lo largo de todo el período ibérico y otro tanto ocurre con las cerámicas de pasta clara (LUZÓN, 1973, 39 ss; PRESEDO, 1982, 297) (4). En cuanto a la cabeza, es aceptado generalmente (NICOLINI, 1973, 60 ss.) que la escultura en piedra apareció en España con posterioridad a la toréutica y que, al parecer, arrancó del Sudeste peninsular, donde se desarrolló bajo la influencia directa del arte griego peninsular. En el caso que nos

(3) Hemos de agradecer la comunicación del hallazgo a la Srıa. Gavilán - quien, además, ha puesto a nuestra disposición de forma absolutamente altruista su Memoria de licenciatura, aún inédita-, así como las facilidades prestadas para su estudio al autor directo del mismo, D. Antonio Moreno Rosa, quien a depositado la pieza en el Museo Arqueológico Municipal de Priego, donde aparece inventariada como MU-157.

El material jbérico recopilado hasta el momento en este Museo ha sido objeto de un estudio provisional por nuestra parte con el título «Notas sobre material ibérico conservado en el Museo Arqueológico Municipal de Priego de Córdoba», ha sido depositado para su publicación en la Revista Corduba Archaeologica del Museo Provincial de Córdoba.

(4) Respecto a los vasos de perfil en $\mathrm{S}$, en el caso concreto de Itálica, por ejemplo, perduran hasta el s. I a. C., arrancando desde el siglo IV (LUZỐN NOGUE, 1970, 39 ss., formas 3 y 9). Sin embargo, en Baza parecen ser más antiguos, a juzgar por las tumbas 31, 121, y 158 (PRESEDO VELO, 1982, 297). Es, pues, un tipo cerámico de muy larga perduración y otro tanto ocurre con las formas de platos, cuencos y posibles lucernas (LUZÓN NOGUE, 1973, 37 ss.)
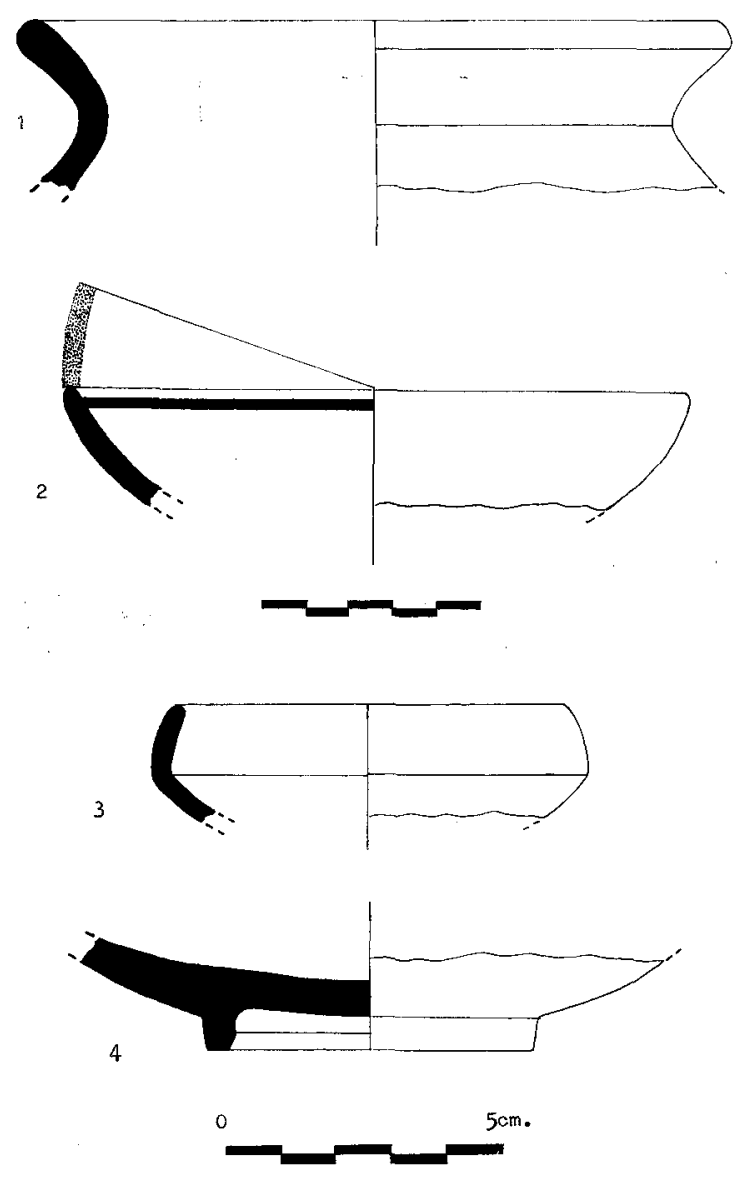

Fig. 4.-Cerámica común a torno de época ibérica recogida en superficie. Pastas claras y cuidadas. Formas de pequeño tamaño relacionables con actos de libación.

ocupa nos hallamos ante una pieza de bulto redondo esculpida en piedra caliza, pero, por su aparición fuera de un contexto fechable estratigráficamente, debe ser datada de forma relativa, por su posible relación con piezas conocidas, $y$, en este sentido, sus paralelos más cercanos los hallamos en el importante yacimiento campiñés de Torreparedones, entre los términos municipales de Castro del Río y Baena, casi en el límite de la Subbética cordobesa (SERRANO y MORENA, 1984, PP. 124-128; láms. III a la LXXII). En dicho lugar se ha hallado hasta el momento un conjunto de 25 figuras de piedra realizadas sobre materiales blandos, en especial calizas con cierto porcentaje de areniscas, y entre ellos observamos tanto el tratamiento de la boca y barbilla mediante un plano biselado (LAM. III), como la característica forma ganchuda de la nariz (LAM. IV). 


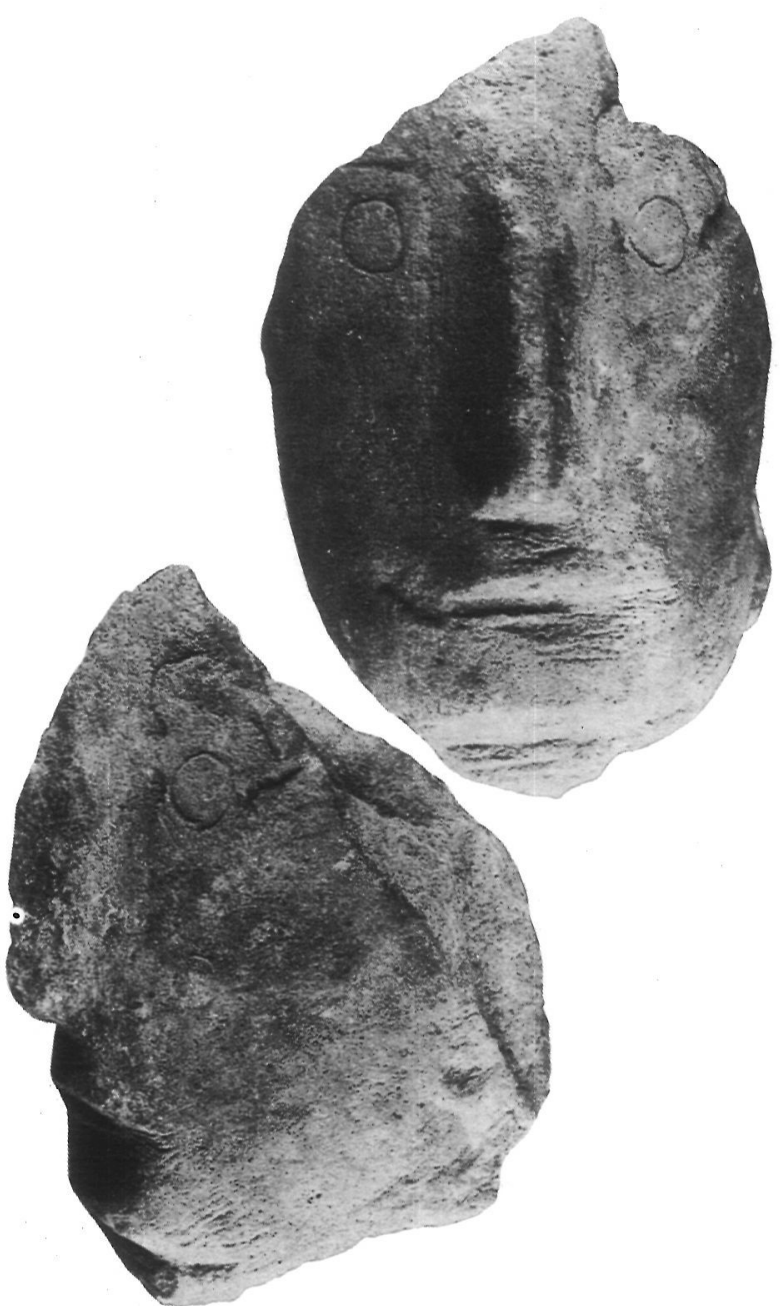

Lám II:Exvoto ibérico de caliza localizado entre los numerosos clastos que, procedentes de los continuos derrumbes de paredes y techo, casi colmatan el vestíbulo de entrada a la Cueva de la Murcielaguina propiamente dicha. Talla muy sumaria.

tanto el tratamiento de la boca y barbilla mediante un plano biselado (LAM. III), como la característica forma ganchuda de la nariz (LAM. IV).

Tal abundancia de exvotos en un lugar que reúne algunas características típicas como elevada altitud y proximidad a manantiales de agua, ha lleva-

(5) SERRANO Y MORENA, 1984, pp. 124-128, láms. LII a la LXXIII: No hemos podido acceder personalmente al análisis de estas piezas debido sobre todo al hecho de que desconocemos su paradero. En la actualidad, existen fundados temores acerca del posible carácter falso de dichas esculturas. Sin embargo, piezas del mismo tipo se hallan recogidas en el Museo Arqueológico Provincial y ante la falta de un estudio detallado de aquéllas preferimos limitarnos a señalarlas, sin entrar para nada en la polémica acerca de su autenticidad.
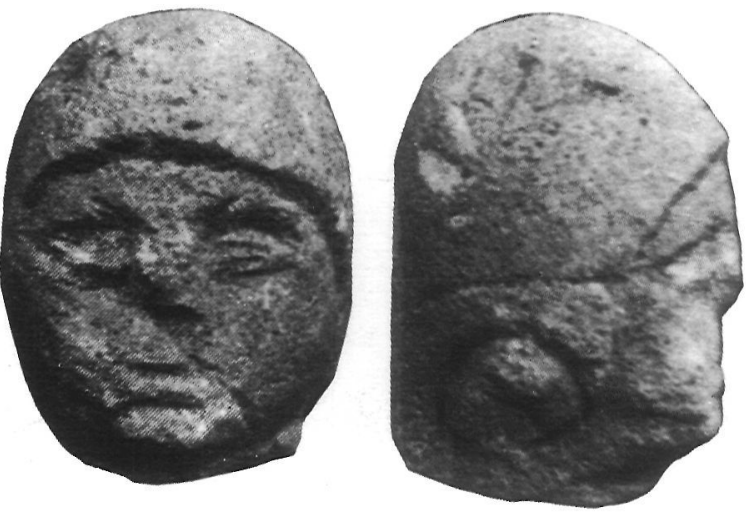

Lám. III:Torreparedones. Exvoto ibérico en caliza. Vista frontal y lateral (Según SERRANO Y MORENA, 1984, láms. LXII y LXIII).

do a sus descubridores a plantear la posibilidad de que allí se ubicara un santuario al estilo - aunque evidentemente a menor escla- de, por ejemplo, Despeñaperros. Desde este mismo punto de vista, la pieza de la cueva sumará nuevos ejemplares, pudo haber sido depositada en Murcielaguina con un cierto sentido votivo que se nos escapa y esto daría pie, como veremos más adelante, a plantear la posibilidad de la identificación de este lugar con una cueva santuario.

Piezas con cierto paralelismo las hallamos también, por tan solo citar algunas, en la Colección de
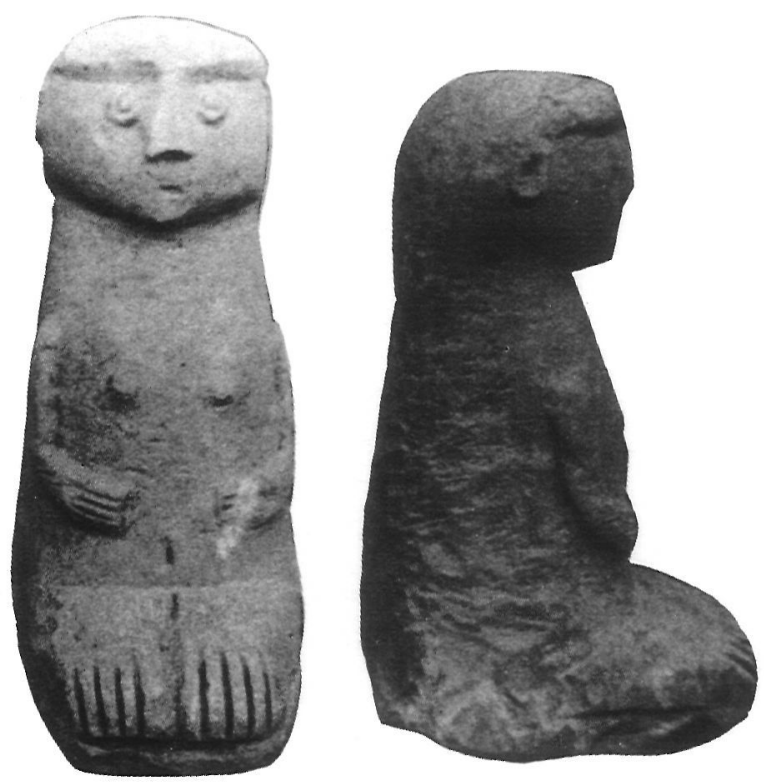

Lám. IV:Torreparedones. Exvoto ibérico femenino. Vista frontal y lateral (Según SERRANO y MORENA, 1984, láms. LXIX y LXX). 


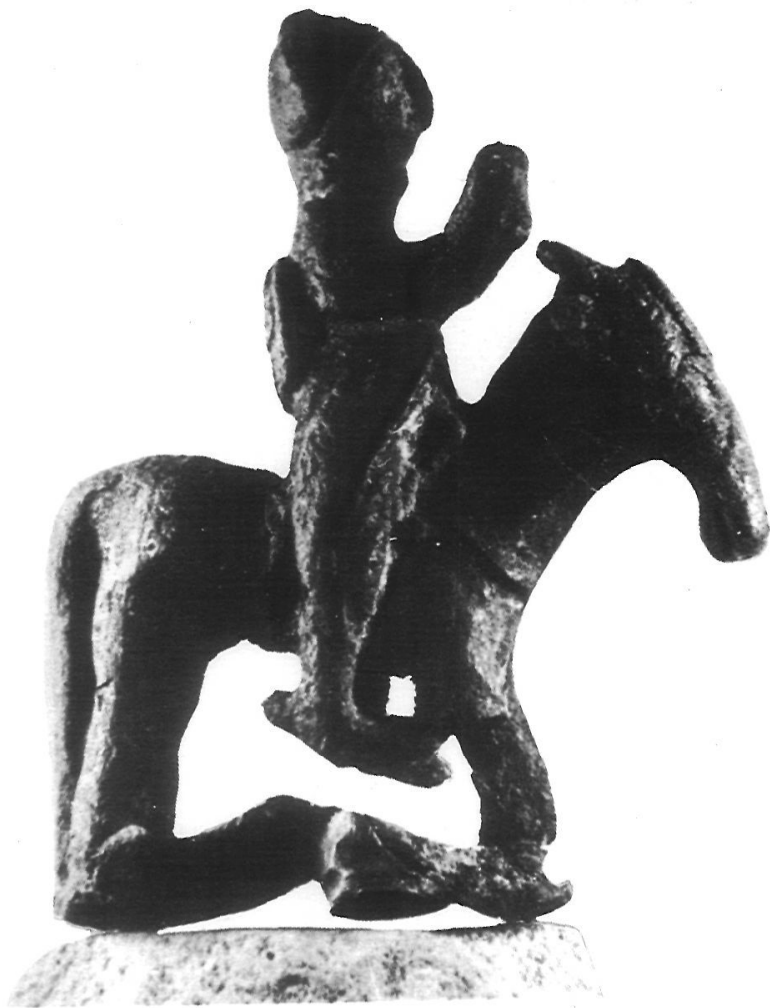

Lám. V: Iinete ibérico en bronce procedente de El Cigarralejo (Murcia). Colección Valencia de D. Juan (Según NICOLINI, 1969, lám. VI, 1).

Valencia de D. Juan (NICOLINI, 1969, 62-63, lám. VI, 1 y 2), en la que un jinete de gran esquematismo procedente del Santuario de Ntra. Sra. de la Luz (El Cigarralejo, Murcia) presente el mismo perfil que la pieza que estudiamos (LAM. V), o en las colecciones procedentes de Despeñaperros (NICOLINI, 1973, 88, fig. 65) caso por ejemplo de dos figuritas femeninas mitradas, también de gran esquematismo, en las que el tratamiento del rostro, especialmente de las cejas y los ojos, es muy similar al de la cabecita de Murcielaguina (LAM. VI). Ambas son fechadas en lo que Nicolini llama época media de la escultura ibérica, aproximadamente entre fines del s. V y comienzos del IV, que se caracteriza por un gran desarrollo de la misma, a la vez que por el nacimiento de nuevos tipos, matizados desde el principio por el carácter esquemático de la nueva producción, por lo general más indígena que la precedente.

Pese a las últimas investigaciones, es muy poco lo que sabemos aún de las religiones indígenas prerromanas. En el área andaluza conocemos la existencia de importantes santuarios como Despeñape- rros, Collado de los Jardines y Castellar de Santisteban, cuya función social, al igual que ocurriría con los del Levante, rebasaría ampliamente los límites de la ciudad o tribu en cuyo territorio se alzaban. Por otra parte, representaciones de la cerámica nos hablan de la celebración de danzas y festejos rituales, así como sacrificios de distinto tipo; las esculturas zoomorfas colocadas ante las tumbas con sentido apotropaico nos indican la existencia de creencias relacionadas con el mundo de ultratumba y las regiones infernales; multitud de exvotos y alguas piezas de gran importancia como la Dama de Baza testimonian cultos diversos a la paloma, el caballo, el toro o una Gran Diosa Madre, relacionada sin duda con la Tierra y los ritos de la fecundidad; etc.
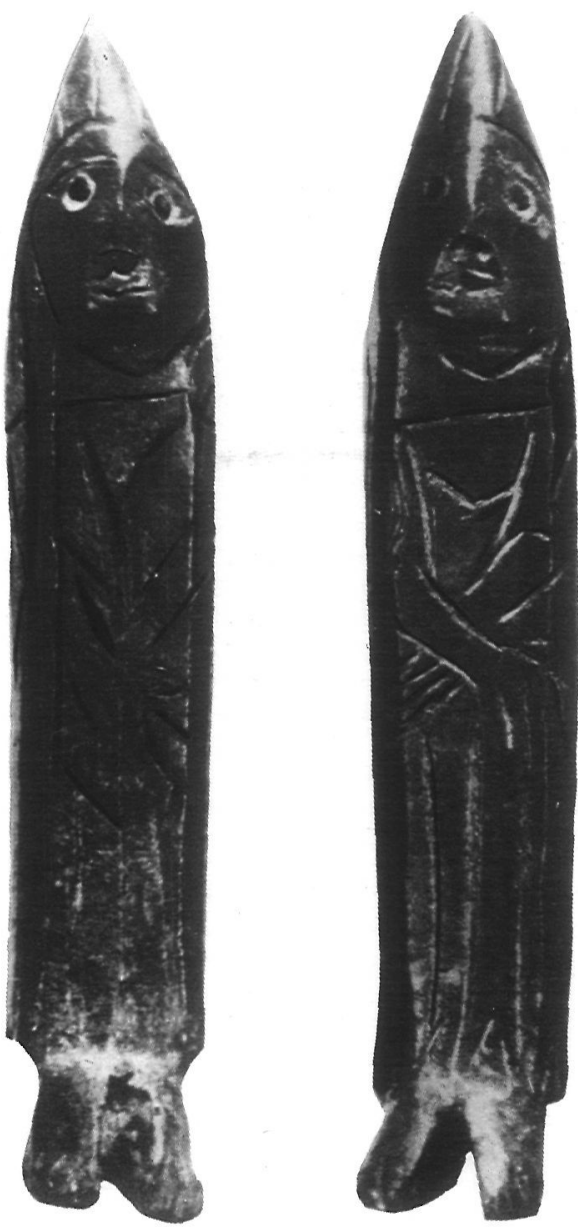

Lám. VI:Exvotos ibéricos de bronce procedentes del Santuario de Despeñaperros. Museo Municipal de Valencia. (Según NICOLINI, 1973, 88, lám. 65). 
Empero, sólo sabemos con certeza que la religión ibérica debió ser el resultado de un fuerte sincretismo entre creencias autóctonas y ritos llegados del área mediterránea y entre estos deben ser incluídos sin duda los practicados en cuevas santuarios, cuyo carácter, fórmulas y objetivos básicos nos son, a pesar de todo, desconocidos.

El fenómeno de la habitación en cuevas en tiempos inmediatamente prerromanos, ya objeto de algunos análisis parciales anteriores (PLA BALLESTER, 1966, 295 ss; GIL-MASCARELL, 1971, 17; LLOBREGAT, 1974, 110 y 132; TARRADELL, 1974, 25 ss.), fue abordado de manera global para el caso valenciano hace una decena de años por M. Gil-Mascarell (GIL-MASCARELL, $1975,281-333$; 1977, 705-713), quien dividió las cuevas ibéricas en cuevas refugio y cuevas santuario (6). Respecto a las primeras destaca la monotonía de sus materiales: platos (que son los recipientes que más abundan), urnas, kalathoi, oinochoi y caliciformes, la mayoría muy fragmentados, debiendo atribuirse a períodos de ocupación temporal o de refugio esporádico.

(6) GIL-MASCARELL, M., 1977, 705-713: En la excavación de esta cueva, que en general se ajusta a todas las características señaladas por la autora para las cuevas santuarios, Gil Mascarell denota particularidades como la presencia en su interior de cenizas y carbones así como estalactitas y estalagmitas. Esto le lleva a ratificarse en su hipótesis de que tal vez pueden señalarse varios subgrupos en este tipo de cuevas y que muy probablemente la elección de cada una de ellas respondió a una función específica que no cumplía cualquier otra cercana. Así pues, si nuestra catalogación de Murcielaguina como cueva santuario se confirma, su elección, entre otras de mayor envergadura y con distintas características, habría tenido lugar por motivos muy concretos como pudiera ser su ubicación en lo alto del Barranco de las Angosturas o su localización centralizada respecto a los principales núcleos ibéricos de la zona. Sin embargo, por el momento estos razonamientos no dejan de ser meras hipótesis de trabajo y sería necesaria tanto una prospección sistemática de las cuevas de la zona -en busca de características comunes a las que llamamos cuevas-santuario - como una excavación en Murcielaguina -empresa inviable por la degeneración morfológica progresiva de la misma - para poder afirmar con cierta base la práctica o no de algunos ritos en esta última, así como la importancia de los mismos en relación con poblados cercanos de la envergadura del Cerro de la Cruz (Almedinilla), el Cerro de Las Cabezas (Fuente Tójar) o el Camino del Tarajal (Priego de Córdoba). En cualquier caso, la zona subbética cordobesa está siendo objeto de una intensa prospección encaminada fundamentalmente a conocer el contexto cultural en el que se enmarca el interesante yacimiento del Cerro de la Cruz, cuya excavación dirigimos desde 1985 , y en breve plazo confiamos en contar con un panorama mucho más clarificador que ayude a conformar culturalmente el importante, pero aún casi desconocido, período ibérico cordobés.
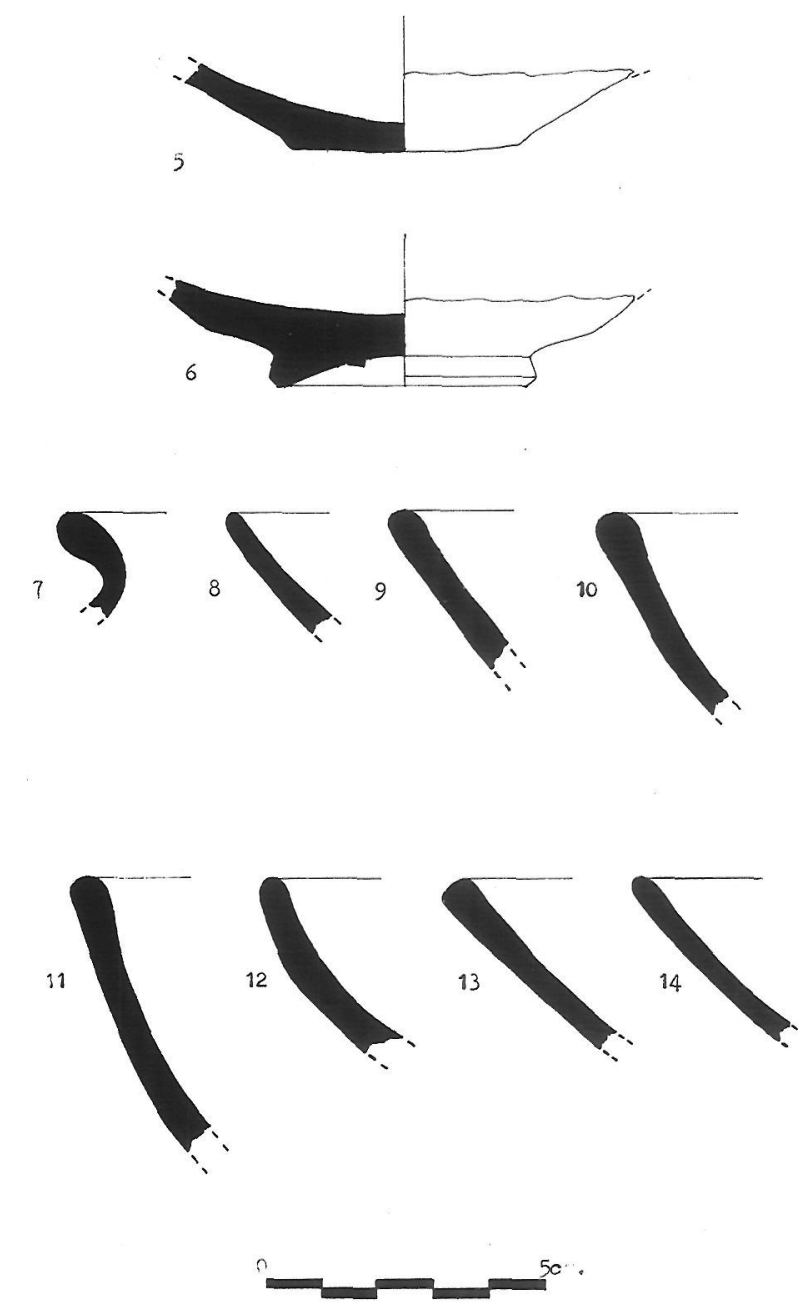

Fig. 5.-Cerámica común a torno de época ibérica. Superficie. Formas cóncavas en relación con el uso ya indicado.

Esto podría llevarnos a atribuir los materiales de Murcielaguina a una ocupación de estas características. Sin embargo, la aparición de un exvoto en piedra caliza -que, como indicamos más arriba no debe ser único, siendo necesaria una revisión sistemática de los numerosos clastos que rellenan la cueva con el objeto fundamental de confirmar o no nuestra hipótesis, al estilo de algunas cuevas del País Valenciano como la Cova de les Meravelles, en Gandía, donde aparecen ídolos de terracota-, nos ha llevado a tratar de analizar sus similitudes con las que Gil-Mascarell Ilama cuevas-santuario $\mathrm{y}$, en este sentido, observamos las siguientes coincidencias y disparidades:

- Gil Mascarell señala como primera característica de las cuevas santuario la presencia sistemá- 
tica y casi exclusiva en todas ellas de vasitos ibéricos caliciformes de pasta gris, recipientes que sin duda debieron servir como vasos de ofrendas y libaciones. En Murcielaguina sólo encontramos un ejemplar de estas características, pero, por el contrario, abundan los platos, vasos, copas y pequeños cuencos que son el segundo elemento que unifica estas cuevas y que, muy probablemente, tuvieron el mismo uso, a excepción quizá de los utilizados como lucernas.

- En todos los casos los materiales se sitúan en los lugares inaccesibles del interior de las cuevas, bien por su profundidad, bien por la dificultad de llegada a las mismas. En Murcielaguina, como sabemos, estos materiales aparecen con especial profusión en el vestíbulo y en una de las salas interiores. Sin embargo, no hay que olvidar que los numerosos derrumbes han desfigurado el aspecto original de la cueva y, por otra parte, argumentos positivos para su elección como «santuario» serían su ubicación en uno de los puntos más altos de las Angosturas - desde donde se contempla una preciosa panorámica del Barranco y del curso del río Salado, así como de la cadena montañosa próxima-y la elección ya primitiva de sus paredes para numerosas pinturas rupestres, entre las que destaca un ídolo oculado que se ha relacionado con el culto mediterráneo a la Diosa Madre o Diosa de los Ojos (7). En cualquier caso, no se trata de argumentos concluyentes desde el momento en que pinturas aparecen también por ejemplo en Cholones y Murciélagos.

- Por regla general, los poblados conocidos en las proximidades de una cueva-santuario se localizan a una distancia mínima de $5 \mathrm{Kms}$. de la misma y a todos los efectos parece darse más bien una relación poblados-cueva que cueva-poblado. En el caso de Murcielaguina esta característica se cumple por completo ya que no conocemos nigún poblado importante en sus alrededores y sólo a alguna distancia podemos citar el del Camino del Tarajal, junto a la aldea del mismo nombre, los Castillejos y el Cerro de la Cruz, en Almedinilla y el

(7) Argumentos que avalan la hipótesis de ciertas prácticas religiosas entroncadas con los primeros momentos del Neolítico podrían ser también la abundancia de esteliformes en las cerámicas incisas recogidas en superficie y el hallazgo de un raspador decorado con un cuadrúpedo inciso que actualmente se conserva en el Museo Arqueológico Municipal de Priego de Córdoba y que ha sido objeto de estudio por parte de B. Gavilán (en prensa).
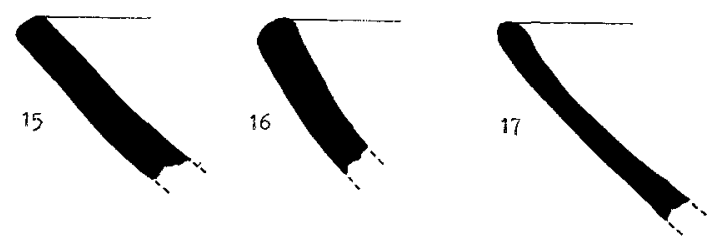

18
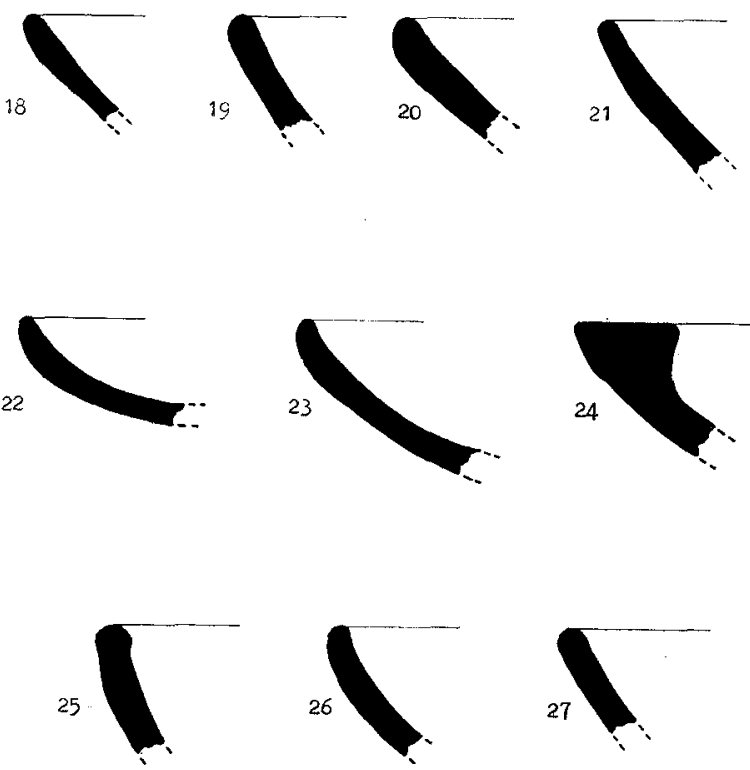

0

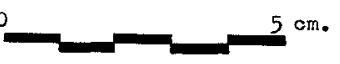

Fig. 6.-Cerámica común a torno de época ibérica. Superficie. Platos, cuencos y posibles lucernas. Predominio casi absoluto de los bordes redondeados, sólo en ocasiones entrantes y a veces engrosados.

Cerro de las Cabezas, en Fuente Tójar. En esta zona de la Subbética el número de recintos fortificados que caracteriza el mundo de la Campiña se hace más espaciado y la no elección de cualquier otra cueva, incluso con pinturas rupestres como acabamos de señalar, tal vez indica una plena voluntariedad y consciencia a la hora de centralizar en Murcielaguina esos ritos ibéricos que, en esencia, siguen escapando a nuestro conocimiento.

- De modo habitual, las que Gil-Mascarell cataloga como cuevas-santuario presentan escasez de materiales. Este no es estrictamente el caso de Murcielaguina, donde es muy posible que aparezca mucho más material si se procede a su limpieza. 
Sin embargo, no hay que perder de vista el hecho de que en la mayor parte de las cuevas estudiadas dicha autora chocó con el importante problema del expolio y, por ello, es preciso destacar la relatividad de esta característica.

- Por último, desde el punto de vista cronológico, y en base a las cerámicas importadas, la autora citada fecha la utilización de las cuevas rituales valencianas desde finales del s. V a. C., señalando su uso regular durante todo el s. IV, a partir del cual el proceso cronológico se pierde. Se da, pues, una coincidencia absoluta entre las fechas propuestas por ella y la propuesta por nosotros para la cabecita de piedra caliza también hallada en Murcielaguina y éste constituye quizá el argumento de más peso a la hora de catalogar esta cueva cercana a Priego como posible cueva santuario.

En definitiva, la cabecita de Murcielaguina, si bien no permite concluir su carácter votivo de manera terminante hasta là aparición de nuevos ejemplares, sí al menos constituye el único ejemplar de escultura ibérica conocida en la comarca prieguense y un interesante argumento para plantear la hipótesis de que esta cueva pudiera haber sido utilizada como santuario por un pueblo de cuya religión, ritos y actos ceremoniales apenas podemos sino esbozar un cuadro excesivamente generalizado... Gil-Mascarell señalaba en su artículo la localización de cuevas rituales con exclusividad en el País Valenciano. Nosotros pensamos que en el S. peninsular este fenómeno pudo ser igualmente factible y la cueva de la Murcielaguina constituiría así una buena muestra de ello, por lo que quizás en un futuro no muy lejano sea posible trazar un cuadro de cuevas rituales en todo el espacio cultural ibérico, plantear el origen y evolución de dicho fenómeno religioso y, a la vez, ampliar nuestro conocimiento sobre la mentalidad de un pueblo de cuyo carácter social, humano y espiritual sólo podemos juzgar por el momento a través de su cultura material.

\section{BIBLIOGRAFÍ A}

BERNIER, J.; FORTEA, F. J., 1968-1969: «Nuevas pinturas rupestres esquemáticas en la provincia de Córdoba. Avance de su estudio», Zephyrus XIX-XX, 143-165.

CARRASCO, J.; CARRASCO, E.; MEDINA, J.; TORRRECILLAS, J. F., 1985: El fenómeno mupestre esquemático en la Cuenca Alta del Guadalquivir. I Las Sierras Subbéticas, Prehistoria Giennense 1, Granada, 80-81, figs. 70 a 75.

GAVILÁN CEBALLOS, B., 1983: Aspectos del Neolítico en el Sureste de Córdoba. Memoria de Licenciatura leída en la Facultad de Filosofía y Letras de Córdoba. (Inédita).

- 1984: «La Cueva de La Murcielaguina de Priego (Córdoba): Análisis de un asentamiento neolítico». Arqueología Espacial. Coloquio sobre distribución y relaciones entre los asentamientos. Vol. 3, Teruel.

GIL-MASCARELL, M., 1971: Yacimientos ibéricos en la región valenciana. Estudio del poblamiento. (Resumen de Tesis Doctoral), Valencia.

- 1975: "Sobre las cuevas ibéricas del País Valenciano». Papeles del Laboratoio de Arqueología de Valencia 11 , L-Aniversario de la Fundación del Lab. de Arq. (19241974), 281-333.

- 1977: «Excavaciones en la cueva ritual ibérica de Villagordo del Cabriel (Valencia)», XIV C.A.N., Vitoria 1975, Zaragoza, 705-713.

LLOBREGAT, E., 1974: «Recientes hallazgos de época ibérica en Alicante», Anejos de Arch. Esp. de Arqueología VII, Madrid, 110 y 132 .

LÓPEZ ONTIVEROS, A., 1985: Preliminares sobre geografia cordobesa. Ed. Gever, Sevilla.

LUZÓN, J. M., 1973: Excavaciones en Itálica. Estratigrafía en el Pajar de Artillo (Campaña 1970), E.A.E. 78, Madrid.

NICOLINI, G., 1969: Les bronces figurés des sanctuaires ibériques. Presses Universitaires de France, París.

- 1973: L'art et la civilisation de L'Espagne antique. Les ibères. Libraire Arthène Fayard, París.

ORTEGA ALBA, F., 1974: El Sur de Córdoba. Estudio de geografia agraria. 2 Vols. Córdoba.

PLA BALLESTER, E., 1966: «Actividades del S.I.P. en 19611965», Arch. de Preh. Lev. XI, Valencia, 295 ss.

PRESEDO VELO, F., 1982: La Necrópolis de Baza, E.A.E. 119, Madrid.

SERRANO J.; MORENA, J. A.: Arqueología inédita de Córdoba y Jaén. Publ. del Monte de Piedad y Caja de Ahorros de Córdoba, Córdoba.

TARRADELL, M.: «Cuevas sagradas o cuevas-santuario: un aspecto poco valorado de la religión ibérica». Memoria de 1973 del Inst. de Arq. y Preh. de la Universidad de Barcelona. Barcelona, 25 ss. 